\title{
DETECTING FUNCTIONAL DISABILITIES IN ELDERLY PERSONS WITH CARDIOVASCULAR DISEASES USING THE SELF-REPORTING METHOD
}

\author{
DIJANA BABIĆ ${ }^{1}$, ŽELIMIR BERTIĆ ${ }^{2}$, NIVESKA KRIŽANEC ${ }^{1}$, LJILJANA BABIĆ ${ }^{1}$ \\ ${ }^{1}$ Clinic for Cardiovascular Diseases Magdalena, Krapinske Toplice, Croatia, contact: dijana.babic55@gmail.com \\ ${ }^{2}$ Institute of Public Health of Bjelovar-Bilogora County, Bjelovar, Croatia
}

Received: 06.03.2020.

Preliminary report

Accepted: 11.10 .2020 .

UDK: 616.1-053.9

doi: $10.31299 /$ hrri.56.2.10

\begin{abstract}
The ability to perform basic activities of daily living (ADL) and instrumental ADL (IADL) is an essential indicator of the level of functional capacity in old age. The purpose of this paper was to evaluate reliability and validity of the selfreporting method in detecting functional difficulties among elderly persons with cardiovascular diseases. The Groningen Activity Restriction Scale was used to assess the limitations in functional capacity. The sample consisted of patients over the age of 65 with hypertensive disease, angina pectoris, ischaemic heart disease, degenerative valvular disorders, peripheral arterial disease, cardiac arrhythmias, cardiomyopathy and heart failure. The Cronbach's alpha internal consistency coefficient was calculated for the total result. Differences in outcome with respect to age, educational level, marital status, and medical diagnoses of participants were compared by means of a t-test or one-way ANOVA. In the group of ADL, participants reported difficulties in climbing stairs $(M=2.14, S D=1.07)$ and caring for feet and toenails $(M=2.17, S D=1.27)$, while in the group of IADL, difficulties were present in performing heavier household chores $(M=2.51, S D=1.31)$ as well as ironing and washing clothes $(M=2.20, S D=1.29)$. Calculation of the Cronbach's alpha coefficient points to a high degree of internal consistency for this scale on a chosen sample ( $\alpha=0.95)$. The use of a validated self-reporting tool may be a valuable and reliable way for assessing the functional capacity of elderly persons with chronic diseases. The findings of this study indicate the possibility of using this method for prognostic purposes in patients with cardiovascular diseases. Introduction of instrumental support measures in a timely manner has a crucial role in delaying the progression of functional dependence.
\end{abstract}

Key words: functional capacity; assessment; self-reporting; the elderly; chronic disease

\section{INTRODUCTION}

Aging is an inevitable, dynamic and progressive process characterised by numerous changes that affect the physical, psychological and social functioning of an individual (Orimo et al. 2006; World Health Organization 2010; Milanovic et al. 2013; Dziechciaz and Filip 2014). It has already been estimated that life expectancy has reached 78.1 years, while further projections suggest that by 2030 as many as $20 \%$ of the overall population will be 65 years of age or older (Lilley, Collins Rainforth and Snyder 2014).

One of the most significant consequences of aging is a decrease in physical strength and the appearance of limitations in functional capacity that are most often expressed by difficulties in performing daily activities related to maintaining independence and autonomy in everyday life (Milanović et al. 2013; Palma et al. 2014), such as moving, eating, maintaining hygiene or dressing, taking medicines and caring for finances (Beaton and Grimmer 2013; Abdulaziz et al. 2016; Mlinac and Feng 2016; Nielsen et al. 2016). According to available statistical data, it has been determined that $8 \%$ of elderly people living independently need assistance in performing one or more basic daily self-care activities (Kleinpell, Fletcher and Jennings 2008).

A special issue related to advanced age is the appearance of chronic diseases which significantly affect mobility and overall health status, imposing 
lifestyle changes associated with increased risk of injuries, a need for assistance, institutionalisation, and increased use of health and social resources (Michaels Fisher and McCabe 2005; Lee, Lee and Mackenzie 2006; Muszalik, Kedziora-Kornatowska and Kornatowski 2009; Jacob, Breuer and Kostev 2016). The most common diseases which contribute significantly to the appearance of functional limitations include cardiovascular diseases, hypertension, diabetes, tumors, chronic pulmonary diseases and arthritis (Wild, Roglic, Green, Sicree and King 2004; Jacob et al. 2016; Costa Filho, Mambrini, Malta, Lima-Costa and Peixoto 2018).

The presence of a chronic disease affects the lack of functionality through various mechanisms, such as a decrease in mobility, development of cognitive-sensory limitations, absence of normal mechanisms of adaptation to the disease or the inability to adopt compensatory behaviours (Hung, Ross Boockvar and Siu 2012; Colon-Emeric, Whitson, Pavon and Hoenig 2013). This is the reason for the growing interest in research on the strategies of maintaining productivity and independence in old age, which will serve as a basis for the development of measures for the prevention and management of dysfunctions associated with aging (Lunenfeld and Stratton 2013).

Functional difficulties in old age often appear unnoticed over time and are usually spotted accidentally or after the occurrence of an adverse event (Beaton and Grimmer 2013). The limitations in performing daily activities affect the overall physical, psychological and social functioning of an elderly person (Torres, Reis and Reis 2010; Beaton and Grimmer 2013; Nielsen et al. 2016), which is why the definition of the level of functional capacity is an important part of a comprehensive geriatric assessment and the first step in the assessment of the elderly persons' needs for additional support (Souza Freitas et al. 2012; Jiang and Li 2016; Nielsen et al. 2016; Wales, Clemson, Lanvin and Cameron 2016).

The most commonly used methods for measuring the ability to perform activities of daily living (ADLs) and instrumental ADLs (IADLs) include a person self-reporting about his or her own capabilities, reporting by the caregiver or carer, and direct observation of the performance of a certain activity by a professional (Souza Freitas et al. 2012; Mlinac and Feng 2016). There is a number of instruments in use, in the form of questionnaires validated for clinical and scientific use, the most famous being the Barthel Index (Mahoney and Barthel 1965), the Katz Index (Katz 1983) and the LawtonBrody Scale (Lawton and Brody 1969). While these tools are used primarily for separate assessment of basic ADLs or IADLs, a group of authors designed the Groningen Activity Restrictions Scale (GARS) (Kempen, Miedma, Ormel and Molenar 1996), which contains questions for evaluating both groups of activities. Based on the provided answers, the subjects are classified as independent, when they do not need the help of another person, and as dependent to a certain degree, when they require assistance in performing at least one activity within each dimension (Rubio, Lazaro and Sanchez-Sanchez 2009; Souza Freitas et al. 2012; Berlezi et al. 2016). The self-assessment method can be very useful because it provides insight into the level of activity performance, which is difficult to assess personally by a specialist (Bravell, Zarit and Johansson 2011). However, self-reporting is based on the subjective experience of a person and their own perception of their current abilities, which may be influenced by their existing acute health condition and possible imposed limitations (Gill et al. 2010; Nielsen et al. 2016).

In the case of direct observation or performance assessment, researchers use tests that begin with determining a person's cognitive or behavioural abilities to solve everyday tasks or to apply a certain type of behaviour (e.g. using the telephone, taking medication, writing checks) in a controlled environment (Schmitter-Edgecombe, Parsey and Cook 2011). Some of the tests recognized in clinical use, such as The Physical Performance Test - PPT (Reuben and Siu 1990), Direct Assessment of Functional Status - DAFS (Loewenstein et al. 1989) and The Revised Observed Tasks of Daily Living - OTDL-R (Diehl et al. 2005), encompass the performance assessment of ADLs (PPT) and IADLs (PPT, DAFS, OTDL-R). The method of assessment by observing the performance of a specified activity is considered to be more objective, since it provides an insight into specific and sensitive components of performing a particular 
action that may indicate changes in functional abilities before the real problem arises (Nielsen et al. 2016; Mlinac and Feng 2016). However, this form of assessment requires a higher level of education and training for the persons conducting the data collection, while the results might depend on current motivation, cognitive capacity and state of mind of the respondents (Mlinac and Feng 2016).

\section{AIM}

The aim of this paper is to determine the applicability and reliability of the self-assessment method in detecting functional difficulties among elderly persons with cardiovascular diseases.

\section{Problems and hypotheses}

The presence of cardiovascular disease accelerates the occurrence of functional limitations among elderly persons. One of the most important steps in the prevention of further functional decline is an assessment of currently present limitations. Evaluation of difficulties in performing ADLs and IADLs is a simple way to determine the presence of limitations in functional capacity.

Therefore, we set the following research hypotheses:

H1 The presence of cardiovascular disease affects the functional capacity of the elderly

H2 The decline of functional capacity in old age is influenced by sociodemographic factors

H3 Self-assessment of functional capacity is an applicable and reliable method for determining functional limitations among elderly persons with cardiovascular diseases.

\section{METHODS}

For the purpose of assessing functional capacity among respondents, the Groningen Activity Restriction Scale was used. The scale consists of 18 questions, 11 of which are related to the execution of basic ADLs and 7 are related to maintaining IADLs (Table 3). Each question can be answered with five provided answers that indicate the presence or absence of difficulty in performing a specific daily self-care activity. Each of the offered answers carries a certain number of points (one to three), while the complete inability to perform a particular activity is scored with four points. The total score on the scale ranges from 18 to 72 points, with a higher score indicating a higher level of impairment in functionality or lack of independence of the affected person. Psychometric characteristics of the GARS scale were previously tested in the study by Suurmeijer et al. (1994) conducted on patients with rheumatoid arthritis, whose results showed a high degree of reliability $($ rho $=0.94)$ and applicability of this instrument in comparative and longitudinal research across different settings. Also, the validation of the GARS scale conducted by Wales, Lannin, Clemson and Cameron (2018) confirmed its validity and internal consistency in assessing functional capacity in hospitalised older adults.

Data are presented in the tables below. The Kolmogorov-Smirnov test was used to assess data normality. Descriptive statistics were used for presenting sociodemographic and clinical characteristics of the sample. Categorical variables were shown as frequencies with the corresponding percentages. Quantitative variables were presented as means (M) and standard deviations (SD). Cronbach's alpha coefficient of internal consistency was calculated for the total score. Intraclass Correlation Coefficient was calculated to additionally validate the association between the total score with all questions. Differences in calculated scores between different groups in terms of gender, education level, marriage status, medical diagnoses and age were assessed with an independent t-test or one-way ANOVA (in cases when more than two categories existed). All p-values below 0.05 were considered significant. The statistical software IBM SPSS Statistics (version 25) was used in all statistical procedures.

The study included a total of 84 patients undergoing hospital treatment in the period between April and June 2019 at the cardiology departments. Inclusion criteria were the following: age $65+$ years, history of at least one chronic cardiovascular disease, ability to understand and read the questions asked, and expressed willingness to participate in the study. Only questionnaires completed in full were included in the analysis. After the adjustment of inclusion criteria and exclusion 
of partially completed questionnaires, the study included a total of 71 respondents. The sample consisted of $42 \%(n=30)$ women and $58 \%(n=41)$ men. According to their age, the respondents were divided into four groups: 65 to 70 years (18\%), 71 to 75 years $(34 \%), 76$ to 80 years $(31 \%)$, and over 80 years of age $(17 \%)$. Most respondents had a lower and medium level of education $(75 \%)$, lived in a marital community (69\%), and often shared their household with a partner or adult children and grandchildren (77\%). The questionnaire was filled out independently by the participants or with the assistance of the departments' nurses. The survey entailed forms in which the participants answered all given questions in full. Our study was approved by a suitably constituted Ethics Committee of the Clinic for Cardiovascular Diseases Magdalena and it conformed to the provisions of the Declaration of Helsinki in 1995 (as revised in Edinburgh 2000). Participans gave informed consent and patient anonymity was preserved.

\section{RESULTS AND DISCUSSION}

Table 1 shows an overview of the overall number of points gathered by applying the Groningen scale with regard to the age and gender, education level, social status and diagnosis of the chronic cardiovascular disease of the participant.

A summary of the overall results obtained by the application the GARS showed a significant statistical correlation between the number of points on the scale and the gender or educational status of the respondents. Lower levels of functionality were reported more frequently by female respondents $(\mathrm{M}=33.60 ; \mathrm{SD}=14.65 ; \mathrm{p}=0.01)$ and persons with a lower educational status $(\mathrm{M}=35.45 ; \mathrm{SD}=14.37$; $\mathrm{p}=0.01$ ).

As shown in the table, the maximum number of points on the GARS achieved by the participants was 63 , with no age group being statistically distinct according to the range of points. Figure 1 shows the distribution of the total scores of the selected group of respondents, with only a small number $(\mathrm{n}=14,19.7 \%)$ reporting no restrictions on daily activities, while the rest experienced different degrees of difficulties in performing a certain number of activities.

The different groups of cardiovascular diseases also did not significantly affect the total score,

Table 1. Overview of the results of the Groningen scale (GARS) according to participant features

\begin{tabular}{|c|c|c|c|c|}
\hline Groningen scale - total score & $\mathbf{N}$ & $\mathbf{M}$ & SD & $\mathbf{P}$ \\
\hline Man & 41 & 25.98 & 10.04 & \multirow[t]{2}{*}{0.01} \\
\hline Woman & 30 & 33.60 & 14.65 & \\
\hline Unqualified worker & 22 & 35.45 & 14.37 & \multirow[t]{3}{*}{0.01} \\
\hline Worker with medium expertise/qualifications & 31 & 27.55 & 11.03 & \\
\hline High/higher expertise/qualified workers & 18 & 24.39 & 10.62 & \\
\hline Married/In relationship & 49 & 27.49 & 11.24 & \multirow[t]{2}{*}{0.09} \\
\hline Widower/Single & 22 & 33.00 & 15.03 & \\
\hline Living alone & 16 & 31.63 & 13.97 & \multirow[t]{2}{*}{0.38} \\
\hline Living with someone (e.g. partner, children) & 55 & 28.49 & 12.34 & \\
\hline Hypertensive diseases & 9 & 30.89 & 14.89 & \multirow[t]{8}{*}{0.36} \\
\hline Angina pectoris & 20 & 26.80 & 11.05 & \\
\hline Ischaemic heart diseases & 13 & 30.46 & 11.40 & \\
\hline Aortic (valve) stenosis & 5 & 31.60 & 14.33 & \\
\hline Diseases of arteries, arterioles and capillaries & 5 & 32.80 & 17.50 & \\
\hline Cardiac arrhythmias & 14 & 25.57 & 12.83 & \\
\hline Cardiomyopathy and Heart Failure & 2 & 48.50 & 10.61 & \\
\hline Other & 1 & 20.00 & & \\
\hline Age $65-70$ years & 13 & 29.77 & 15.57 & \multirow[t]{4}{*}{0.40} \\
\hline Age $71-75$ years & 24 & 29.13 & 12.71 & \\
\hline Age $76-80$ years & 22 & 26.27 & 9.19 & \\
\hline Age $80+$ years & 12 & 34.08 & 14.74 & \\
\hline
\end{tabular}




\section{Distribution of total scores}

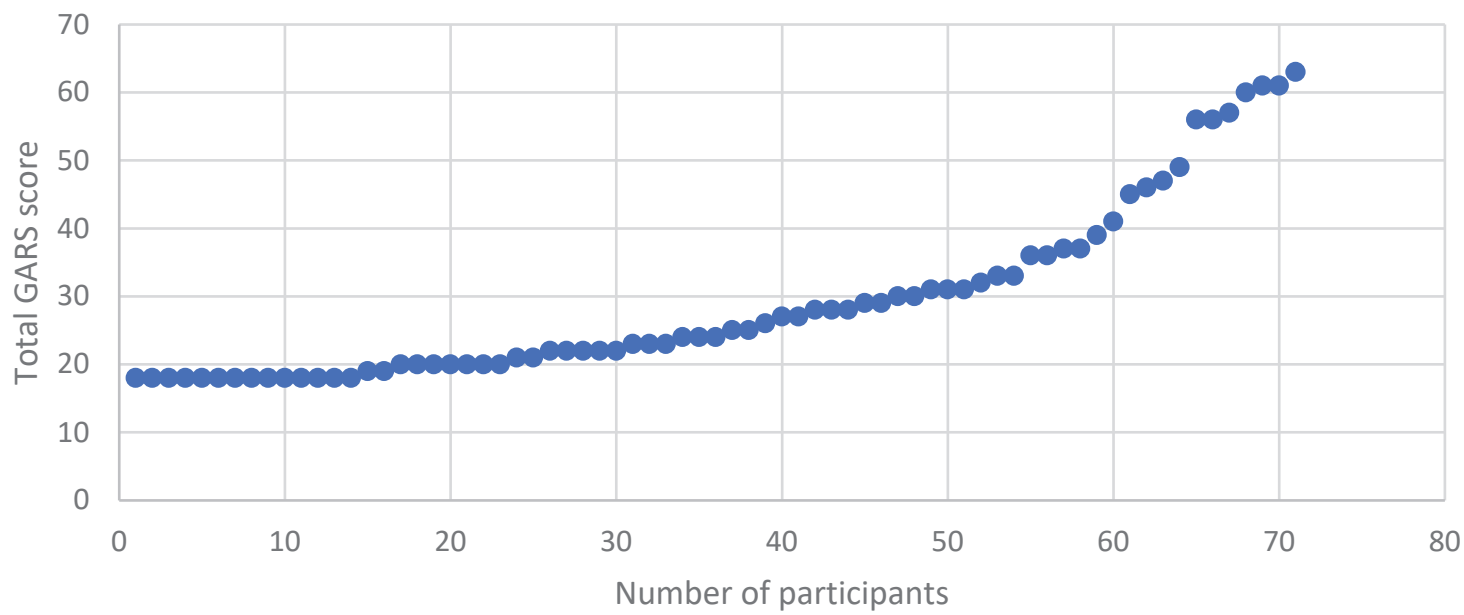

Figure 1. Distribution of total scores

Table 2. A view of the Cronbach's alpha test according to variables

\begin{tabular}{|c|c|c|c|c|c|}
\hline & \begin{tabular}{|l|l} 
Scale Mean if \\
Item Deleted \\
\end{tabular} & $\begin{array}{l}\text { Scale Variance } \\
\text { if Item Deleted }\end{array}$ & $\begin{array}{l}\text { Corrected Item- } \\
\text { Total Correlation } \\
\end{array}$ & \begin{tabular}{|c|}
$\begin{array}{c}\text { Squared Multiple } \\
\text { Correlation }\end{array}$ \\
\end{tabular} & $\begin{array}{c}\text { Cronbach's Alpha } \\
\text { if Item Deleted }\end{array}$ \\
\hline Dressing (ADL) & 27.82 & 144.23 & 0.81 & 0.88 & 0.94 \\
\hline Getting in/out of bed (ADL) & 27.93 & 149.12 & 0.80 & 0.88 & 0.94 \\
\hline $\begin{array}{l}\text { Standing up from chair } \\
\text { (ADL) }\end{array}$ & 27.87 & 148.36 & 0.76 & 0.81 & 0.94 \\
\hline $\begin{array}{l}\text { Washing face and hands } \\
\text { (ADL) }\end{array}$ & 28.14 & 157.55 & 0.46 & 0.52 & 0.95 \\
\hline $\begin{array}{l}\text { Washing/drying the entire } \\
\text { body (ADL) }\end{array}$ & 27.66 & 142.91 & 0.76 & 0.73 & 0.94 \\
\hline $\begin{array}{l}\text { Getting on/up from the toilet } \\
\text { (ADL) }\end{array}$ & 28.00 & 150.17 & 0.77 & 0.88 & 0.94 \\
\hline Eating (ADL) & 28.14 & 158.20 & 0.36 & 0.42 & 0.95 \\
\hline $\begin{array}{l}\text { Getting around inside house } \\
\text { (ADL) }\end{array}$ & 27.79 & 145.79 & 0.76 & 0.81 & 0.94 \\
\hline Climbing stairs (ADL) & 27.06 & 139.94 & 0.78 & 0.76 & 0.94 \\
\hline Walking outdoors (ADL) & 27.48 & 139.51 & 0.83 & 0.82 & 0.94 \\
\hline $\begin{array}{l}\text { Caring for feet/toenails } \\
\text { (ADL) }\end{array}$ & 27.03 & 138.17 & 0.70 & 0.73 & 0.94 \\
\hline $\begin{array}{l}\text { Preparing breakfast/lunch } \\
\text { (IADL) }\end{array}$ & 27.73 & 143.31 & 0.74 & 0.97 & 0.94 \\
\hline Preparing dinner (IADL) & 27.69 & 143.41 & 0.72 & 0.96 & 0.94 \\
\hline $\begin{array}{l}\text { Performing lighter } \\
\text { household chores (IADL) }\end{array}$ & 27.31 & 138.64 & 0.77 & 0.73 & 0.94 \\
\hline $\begin{array}{l}\text { Performing heavier } \\
\text { household chores (IADL) }\end{array}$ & 26.69 & 137.38 & 0.70 & 0.75 & 0.95 \\
\hline $\begin{array}{l}\text { Ironing and washing clothes } \\
\text { (IADL) }\end{array}$ & 27.00 & 137.48 & 0.71 & 0.67 & 0.94 \\
\hline Making the bed (IADL) & 27.66 & 141.88 & 0.77 & 0.73 & 0.94 \\
\hline Shopping (IADL) & 27.35 & 135.57 & 0.81 & 0.75 & 0.94 \\
\hline
\end{tabular}


although it is necessary to emphasise that the lowest points in persons with peripheral vascular $(\min =21, \max =63)$ and ischaemic heart disease or cardiomyopathy $(\min =41, \max =56)$ were initially higher than those of the other disease groups. This information is possibly significant in the context of determining the impact of certain disease groups (peripheral circulatory diseases and chronic heart failure) on functionality in old age.

Table 2 shows the results of the Cronbach's alpha test according to the individual variables of GARS. Statistical analysis of the total score revealed an average of 29.20 points $(\mathrm{SD}=12.68)$. Calculation of the Cronbach's alpha coefficient indicates a high degree of internal consistency of this scale in the selected sample $(\alpha=0.95)$. A relatively large number of variables may correlate with the degree of internal consistency of the scale, since certain claims, e.g. movement inside and outside the household, washing the face and whole body, can be evaluated and understood as similar. However, removing any of the claims did not have a major effect on the total result of the Cronbach's alpha test, as shown in Table $2(\alpha=0.94-0.95)$.

The results of the analysis of variance in individual variables speak in favour of the statistical consistency of the questions, which, in short, adequately measure the same basic concept. By additional calculation of the correlation coefficient between each individual variable and the total score of the scale, a high degree of correlation was obtained ( $\mathrm{ICC}=0.95)$.

Table 3 shows the results of the average score points according to the individual variables of the GARS. Analysis of the average values of individual variables shows that they ranged from 1.05 to 2.50 points $(\mathrm{SD}=0.28-1.29)$; it is important to note that 1 point is equivalent to the assertion of performing a particular activity without difficulty, while 2 points are given to answers that indicate the ability to perform a particular action independently, but with certain difficulties. As can be seen from Table 3, the average score points indicate that the respondents from this group performed most of their daily activities completely independently. Certain difficulties appeared during the performance of activities which required physical effort, a relatively higher level of mobility, movement coordination and flexibility. With regard to the group of ADLs, respondents reported difficulties in climbing stairs $(\mathrm{M}=2.14, \mathrm{SD}=1.07)$ and caring for feet and toenails $(\mathrm{M}=2.17, \mathrm{SD}=1.27)$. The assessment of performing IADLs showed that the participants reported certain difficulties while performing heavier household chores $(\mathrm{M}=2.51, \mathrm{SD}=1.31)$ as well as ironing and washing clothes $(\mathrm{M}=2.20, \mathrm{SD}=1.29)$. Activities such as taking food $(\mathrm{M}=1.06, \mathrm{SD}=0.28)$, independently washing face and hands $(\mathrm{M}=1.06$, $\mathrm{SD}=0.28)$ and getting on and up from the toilet $(\mathrm{M}=1.20, \mathrm{SD}=0.55)$ have been graded with the lowest average number of points. The activities referred to above are those that allow a person to meet basic physiological needs and maintain a minimum level of independence in daily functioning.

Table 3. An overview of the result range according to Groningen scale variables on 71 participants

\begin{tabular}{|l|c|c|}
\hline & M & SD \\
\hline Dressing (ADL) & 1.38 & 0.81 \\
\hline Getting in/out of bed (ADL) & 1.27 & 0.58 \\
\hline Standing up from the chair (ADL) & 1.32 & 0.65 \\
\hline Washing face and hands (ADL) & 1.06 & 0.28 \\
\hline Washing/drying the entire body (ADL) & 1.54 & 0.93 \\
\hline Getting on/up from the toilet (ADL) & 1.20 & 0.55 \\
\hline Eating (ADL) & 1.06 & 0.28 \\
\hline Getting around inside house (ADL) & 1.41 & 0.78 \\
\hline Climbing stairs (ADL) & 2.14 & 1.07 \\
\hline Walking outdoors (ADL) & 1.72 & 1.03 \\
\hline Caring for feet/toenails (ADL) & 2.17 & 1.27 \\
\hline Preparing breakfast/lunch (IADL) & 1.46 & 0.93 \\
\hline Preparing dinner (IADL) & 1.51 & 0.95 \\
\hline Performing lighter household chores (IADL) & 1.89 & 1.15 \\
\hline Performing heavier household chores (IADL) & 2.51 & 1.31 \\
\hline Ironing and washing clothes (IADL) & 2.20 & 1.29 \\
\hline Making the bed (IADL) & 1.54 & 0.98 \\
\hline Doing shopping (IADL) & 1.85 & 1.26 \\
\hline
\end{tabular}

The results show that elderly people with cardiovascular disease had difficulties in performing more physically demanding activities, such as maintaining complex hygiene and doing household chores, but also performing activities that include longer periods of motion, such as doing shopping. At the same time, the results partly indicate the impact that chronic cardiovascular disease has on functionality in older age, in which the ability to tolerate any form of physical exertion is primarily 
compromised. A study by Kattainen et al. (2004) identified a strong association of the presence of cardiovascular diseases, primarily cerebrovascular disease, myocardial infarction and heart failure, with the emergence of limitations in activity and the need for assistance from others in older adults. A study conducted by Duruturk, Tonga, Karatas and Doganozu (2015) also confirmed the impact that the presence of heart disease has on the performance of activities of daily living, especially on walking, climbing up the stairs, bathing, dressing and outings, emphasising the connection between restrictions in physical activity and the overall quality of life.

Applying the self-reporting method for detecting difficulties in the performance of daily activities can give insight into the level of limitations that patients have in their everyday lives that are not visible to the clinician's eye during hospital or outpatient visits. Numerous studies have reported the application of this method to assess functional limitations in different groups of subjects (Brach, Van Swearingen, Newman and Kriska 2002; Latham et al. 2008; Young, Boyd, Guralnik, Bandeen-Roche and Fried 2010; Nielsen et al. 2016). The most common benefits of the self-reporting method are uncomplicated application, reliability, accessibility, and opportunity to provide objective and individual data as well as insights into areas of functioning that are difficult to assess by direct observation (Bravell, Zarit and Johansson 2011; Mlinac and Feng 2016). Nevertheless, Young et al. (2010) found in their study that self-reported level of functionality closely correlates with objective measurements of functional impairment, while self-reported modifications in performing daily work tasks are a valid benchmark in detecting preclinical disability, even in an already disabled population. Latham et al. (2008) conclude that, from a psychometric perspective, any measurement of functionality is appropriate for use in clinical trials that are aimed at defining measures for improving the function of a particular person or group.

In our study, we applied the self-reporting method for the assessment of functional disability among hospitalised elderly patients with cardiovascular disease with highly satisfactory results.
Our approach was aimed at determining the current state of functional disability, as well as the validity and reliability of the chosen measuring instrument, while the study provided by Li et al. (2020) used the self-assessment method as a way to monitor the recovery of functional independence in elderly hospitalised persons after discharge from treatment. A similar purpose was found in a study by Covinsky, Palmer, Fortinsky and Counsell (2003), who successfully applied the self-assessment of ADLs and IADLs in determining changes in functional abilities before and after hospitalisation, simultaneously describing the impact of age on functional capacity loss.

An insight into the total results collected in this study shows a statistically significant difference in scores according to the gender and education level of the respondents. Earlier studies confirmed more frequent reports of the existence of functional limitations, the need for assistance and a higher degree of dependence in performing daily activities in females (Lopes, Lage, Vancini-Campanharo, Okuno and Batista 2015; Hung, Ross, Boockvar and Siu 2011; Berlezi et al. 2016; Millan-Calenti et al. 2010). Differences in functional abilities between genders are explained through the fact that it has been proven that females have longer lifespans and are exposed to a greater number of chronic diseases and other health issues that inevitably compromise their quality of life and the ability to perform different forms of daily activities (Lunenfeld and Stratton 2014; Jindai, Nielson, Vorderstrasse and Quinones 2016).

Sometimes the traditional division of roles within the family, defined primarily by the sociocultural environment, often assumes that female family members are the ones caring for the household, performing numerous difficult tasks necessary for the daily functioning of the family, leaving their own health, education and independence into the background, which ultimately has a long-lasting negative effect on functionality in old age. Guerra, Alvarado and Zunzunegui (2008) state that social inequalities such as poverty, lack of education, lack of income, and dealing with the household during early lifetime are serious causes of functional difficulties in later life, especially in women. However, Schatz, Ralston, Madhavan, Collinson 
and Gomez-Olive (2018) clarify that older people who live in households in which they have to remain productive and active for a longer period of time are exposed to greater levels of functional difficulties with little differences between the genders.

In addition to the impact of gender, it is evident that functionality in older age can be related to the achieved level of education. In their study, Nurrika et al. (2019) confirmed that higher education levels are significantly associated with a lower risk of incident functional disability, whereby participation in community activities has the largest mediating effect on this relationship, especially among elderly persons aged 65 and above. Limited levels of formal education are still quite present among older people, especially in economically less developed countries (Brigola et al. 2019). Brigola et al. (2019) stated that more years of formal education are directly linked to better cognitive test scores, improved functional abilities, and lower risk of developing fraility syndrome among older adults. It can be said that the level of education generally determines the socio-economic position of an individual early in adulthood and defines the availability of personal resources, which together influence long-term patterns of exposure to numerous psychosocial and biomedical risk factors, such as the use of preventive and therapeutic health care, adoption of positive health behaviors, control of chronic and acute stress, management of social relationships and social support, and exposure to physical hazards in the home and immediate environment (Zimmer and House 2003).

The appearance of chronic diseases in old age is an inevitable risk factor for the emergence of functional impairment and difficulties in performing daily activities (Jindai et al. 2016; Booth, Roberts and Laye 2012). When considering the influence of chronic cardiovascular diseases on the limitations in performing ADLs and IADLs, Ahto et al. (1998) explained that the functional limitations occur due to the presence of chest pain, dyspnea, depression and the use of numerous cardiovascular medications that affect mobility and toleration of physical effort. Keeney, Fox, Jette and Jette (2019), although they did not use the same measurement instruments, confirmed that the presence of cardiovascular disease increases the risk of a rapid functional decline, especially in females, the elderly, and those with lower levels of education. Consequently, it can be assumed that self-reporting tools like the GARS can serve as an important prognostic aid, which, along with other parameters, can be the basis for assessing the degree of disease progression. Moreover, Dunlay et al. (2015) emphasise that the assessment of performing basic and instrumental self-care activities, which is easily applicable during outpatient visits, is a significant prognostic marker in patients with chronic heart failure and can, as such, serve as a means to assess therapeutic options and disease prognosis.

This study has several limitations. In the first place, this study was conducted on a relatively small sample of elderly persons with cardiovascular diseases, which limits inferences about broader applicability of the results. Second, the procedure of self-assessment of functionality may have been influenced by several subjective factors, such as the current health status and severity of illness, difficulties in linking questions to the offered answers as well the fact that subjects with limited mobility were helped by other persons to complete the questionnaire. It should be emphasised that the study was conducted during the hospitalisation of participants, which certainly affected the objectivity of the assessment. Third, since the study involved elderly persons with mainly multiple chronic conditions, it should be noted that possible changes in psycho-cognitive status that could affect judgment have not been investigated in more detail.

\section{CONCLUSION}

The conducted research shows that the self-reporting method using a validated scale offers reliable information about the existence of functional limitations in the elderly with cardiovascular diseases. Such information can serve for the design and implementation of structured instrumental support measures aimed to delay further functional decline among this specific group of elderly.

\section{ACKNOWLEDGEMENTS}

We sincerely thank all study participants for taking part in this study as well as registered nurses for helping with data collection. 


\section{LITERATURE}

Abdulaziz, K., Perry, J.J., Taljaard, M., Emond, M., Lee, J.S, Wilding, L., Sirois, M.-J., Brehaut J. (2016). National Survey of Geriatricians to Define Functional Decline in Elderly People with Minor Trauma. Canadian Geriatrics Journal, 19(1), 2-8. doi: 10.5770/cgj.19.192.

Ahto, M., Isoaho, R., Puolijoki, H., Laippala, P., Romo, M., Kivela, S.L. (1998). Functional abilities of elderly coronary heart disease patients. Ageing Clinical and Experimental Research, 10(2), 127-36. doi:10.1007/BF03339647.

Beaton, K., Grimmer, K. (2013). Tools that assess functional decline: systematic literature review update. Clinical Interventions in Ageing, 8, 485-494. doi:10.2147/CIA.S42528.

Berlezi, E.M., Farias, A.M., Dallazen, F., Oliveira, K.R., Pillatt, A.P., Fortes, C.K. (2016). Analysis of the functional capacity of elderly residents of communities with a rapid population ageing rate. Revista Brasileira de geriatria e Gerontologia, 19(4), 643-52. doi:10.1590/1809-98232016019.150156.

Booth, F.W., Roberts, C.K., Laye, M.J. (2012). Lack of exercise is a major cause of chronic diseases. Comprehensive Physiology, 2(2), 1143-1211. doi:10.1002/cphy.c110025.

Brach, J.S., Van Swearingen, J.M., Newman, A.B., Kriska, A.M. (2002). Identifying Early Decline of Physical Function in Community-Dwelling Older Woman: Performance Based and Self-Report Measures. Physical Therapy, 82(4), 320-328. doi: 10.1093/ptj/82.4.320.

Bravell, M.E., Zarit, S.H., Johansson B. (2011). Self-reported activities of daily living and performance -based functional ability: a study of congruence among oldest old. European Journal of Ageing, 8(3), 199-209. doi: 10.1007/s10433-011-0192-6.

Brigola, A.G., Alexandre, T.D.S., Inouye, K., Yassuda, M.S., Pavarini, S.C.I., Mioshi, E. (2019). Limited formal education is strongly associated with lower cognitive status, functional disability and frailty status in older adults. Dementia and Neuropsychologia, 13(2), 216-224.

doi: 10.1590/1980-57642018dn13-020011.

Colon-Emeric, K., Whitson, H.E., Pavon, J., Hoenig, H. (2013). Functional Decline in Older Adults. American Family Physician, 188(6), 388-394.

Costa Filho, A.M., Mambrini, J.V.M., Malta, D.C., Lima-Costa, M.F., Peixoto, S.V. (2018). Contribution of chronic diseases to the prevalence of disability in basic and instrumental activities of daily living in elderly Brazilians: the National Health Survey (2013). Cadernos de Saude Publica, 34(1), e00204016. doi:10.1590/0102-311x00204016.

Covinsky, K.E., Palmer, R., Fortinsky, R.H., Counsell, S.R. (2003). Loss of Independence in Activities of Daily Living in Older Adults Hospitalized with Medical Illnesses: Increased Vulnerability with Age. Journal of American Geriatrics Society, 51(4), 451-458. doi:10.1046/j.1532-5415.2003.51152.x.

Diehl, M., Marsiske, M., Horges, A.L., Rosenberg, A., Saczynski, J.S., Willis, S.L. (2005). The Revised Observed Terms of Daily Living. A Performance-Based Assessment of Everyday Problem Solving in Older Adults. Journal of Applied Gerontology, 24(3), 211-230. doi:10.1177/0733464804273772.

Dunlay, S.M., Manemann, S.M., Chamberlain, A.M., Cheville, A.L., Jiang, R., Weston, S.A., Roger, V.L. (2015). Activities of daily living and outcomes in heart failure. Circulation: Heart Failure, 8(2), 261-267. doi:10.1161/ CIRCHEARTFAILURE.114.001542.

Duruturk, N., Tonga, E., Karatas, M., Doganozu, E. (2015). Activity performance problems of patients with cardiac disease and their impact on quality of life. Journal of Physical Therapy Science, 27, 2023-2028.

Dziechciaz, M., Filip, R. (2014). Biological psychological and social determinants of old age: Bio-psychosocial aspects of human ageing. Annals of Agricultural and Environmental Medicine, 21(4), 835-838. doi.10.5604/12321966.1129943.

Gill, T.M. (2010). Assessment of Function and Disability in Longitudinal Studies. Journal of American Geriatric Society, 58(Suppl 2), 308-312. doi:10.1111/j.1532-5415.2010.02914.x. 
Guerra, R.O., Alvarado, B.E., Zunzunegui, M.V. (2008). Life course, gender and ethnic inequalities in functional disability in a Brazilian urban elderly populatio. Ageing Clinical and Experimental Research, 20(1), 53-61. doi:10.1007/BF03324748

Hung, W.W., Ross, J.S., Boockvar, K.S., Siu, A.L. (2011). Recent trends in chronic disease, impairment and disability among older adults in the United States. BMC Geriatrics, 11(1).

doi:10.1186/1471-2318-11-47.

Hung, W.W., Ross, J.S., Boockvar, K.S., Siu, A.L. (2012). Association of chronic diseases and impairments with disability in older adults: a decade of change?. Medical Care, 50(6), 501-507.

doi:10.1097/MLR.0b013e318245a0e0.

Jacob, L., Breuer, J., Kostev, K. (2016). Prevalence of chronic diseases among older patients in German general practice. German Medical Science, 14, Doc03. doi: 10.3205/000230.

Jiang, S., Li, P. (2016). Current Development in Elderly Comprehensive Assessment and Research Methods. BioMed Research International, ID:528248. doi:10.1155/2016/3528248.

Jindai, K., Nielson, C.M., Vorderstrasse, B.A., Quinones, A.R. (2016). Multimorbidity and Functional Limitations Among Adults 65 or Older, NHANES 2005-2012. Preventing Chronic Disease, 13, 160174. doi:10.5888/ pcd13.160174.

Kattainen, A., Koskinen, S., Reunanen, A., Martelin, T., Knekt, P., Aromaa A. (2004). Impact of cardiovascular diseases on activity limitations and need for help among older persons. Journal Clinical Epidemiology, 57(1), 82-88. doi:10.1016/S0895-4356(03)00252-X.

Katz, S. (1983). Assessing self-maintenance: activities of daily living, mobility, and instrumental activities of daily living. Jounal of American Geriatric Society, 31(12), 721-77.

doi:10.1111/j.1532-5415.1983.tb03391.x.

Kempen, G.I.J.M., Miedma, I., Ormel, J., Molenar, W. (1996). The assessment of disability with the Groningen activity restriction scale. Conceptual framework and psychometric properties. Social Science and Medicine, 43(11), 16011610. doi:10.1016/S0277-9536(96)00057-3.

Keeney, T., Fox, A.B., Jette, D.U., Jette, A. (2019). Functional Trajectories of Persons with Cardiovascular Disease in Late Life. Journal of American Geriatrics Society, 67, 37-42. doi:10.1111/jgs.15584.

Kleinpell, R.M., Fletcher, K., Jennings, B.M. (2008). Reducing functional decline in hospitalized elderly. In: R.G. Hughes (ed.), Patient safety and quality. An evidence-based handbook for nurses. Rockville: Agency for Healthcare Research and Quality.

Latham, N.K., Mehta, V., Nguyen, A.M., Jette, A.M., Olarsch, S., Papanicolau, D., Chandler, J. (2008). Performancebased or self-report measures of physical function: which should be used in clinical trials of hip fracture patients?. Archives of Physical Medicine and Rehabilitation, 89(11), 2146-2155. doi: 10.1016/j.apmr.2008.04.016.

Lawton, M.P., Brody, E.M. (1969). Assessment of older people: self-maintaining and instrumental activities of daily living. Gerontologist, 9(3), 179-86. doi:10.1093/geront/9.3_Part_1.179.

Lee, I.F.K., Lee, D.S.T.F., Mackenzie, A.E. (2006). Correlates in functional limitations in older Chinese patients with chronic obstructive pulmonary disease in Hong Kong. Heart and Lung, 35(5), 324-333. doi: 10.1016/j. hrtlng.2006.05.004.

Li, X., Zheng, T., Guan, Y., Li, H., Zhu, K., Shen, L., Yin, Z. (2020). ADL recovery trajectory after discharge and its predictors among baseline-independent older inpatients. BMC Geriatrics, 20, 86. doi.org/10.1186/s12877-020$1481-8$.

Lilley, L.L., Collins Rainforth, S., Snyder, J.S. (2014). Pharmacology and the Nursing Process, Seventh Edition. St.Louis: Elsevier Mosby. 
Loewenstein, D.A., Amigo, E., Duara, R., Guterman, A., Hurwitz, D., Berkowitz, N., Wilkie, F., Weinberg, G., Black, B., Gittelman, B., Eisdorfer, C. (1989). A New Scale for the Assessment of Functional Status in Alzheimer's Disease and Related Disorders. Journal of Gerontology, 44(4), 114-121. doi.10.1093/geronj/44.4.P114.

Lopes, M.C., Lage, J.S., Vancini-Campanharo, C.R., Okuno, M.F., Batista, R.E. (2015). Factors associated with functional impairment of elderly patients in the emergency departments. Einstein(Sao Paulo), 13(2), 209-214. doi:10.1590/S1679-45082015AO3327.

Lunenfeld, B., Stratton P. (2013). The clinical consequences of an ageing world and preventive strategies. Best Practice and Research Clininical Obstetrics and Gynaecology, 27(5), 643-59.

doi:10.1016/j.bpobgyn.2013.02.005.

Mahoney, F.I., Barthel, D.W. (1969). Functional evaluation: the Barthel index: a simple index of independence useful in scoring improvement in the rehabilitation of the chronically ill. Maryland State Medical Journal, 14, 61-65.

Michaels Fisher, H., McCabe, S. (2005). Managing Chronic Conditions for Elderly Adults: The VNS CHOICE Model. Health Care Financing Review, 27(1), 33-45.

Milanović, Z., Pantelić, S., Trajković, N., Sporiš, G., Kostelić, R., James, N. (2013). Age-related decrease in physical activity and functional fitness among elderly men and women. Clinical Interventions in Aging, 8, 549-556. doi:10.2147/CIA.S44112.

Millan-Calenti, J.C., Tubio, J., Pita-Fernandez, S., Gonzalez-Abraldes, I., Lorenzo, T., Fernandez-Arruty, T., Maseda, A. (2010). Prevalence of functional disability in activities of daily living (ADL), instrumental activities of daily living (IADL) and associated factors, as predictors of morbidity and mortality. Archives of Gerontology and Geriatrics, 50, 306-10. doi: 10.1016/j.archger.2009.04.017.

Mlinac, M.E., Feng, M.C. (2016). Assessment of activities of daily living, self-care, and independence, Archives of Clinical Neuropsychology, 31(6), 506-516. doi:10.1093/arclin/acw049.

Muszalik, M., Kedziora-Kornatowska, K., Kornatowski, T. (2009). Functional assessment and health-related quality of life (HRQOL) of elderly patients on the basis of the functional assessment of chronic illness therapy (FACIT)-F questionnaire. Archives of Gerontology and Geriatrics, 49(3), 404-408.

doi: 10.1016/j.archger.2008.12.007.

Nielsen, L.M., Kirkegaard, H., Ostergaard, L.G., Bovbjerg, K., Breinholt, K., Maribo, T. (2016). Comparison of selfreported and performance-based measures od functional ability in elderly patients in an emergency department: implications for selelction of clinical outcome measures. BMC Geriatrics, 16(1), 199. doi: 10.1186/s12877-0160376-1.

Nurrika, D., Zhang, S., Tomata, Y., Sugawara, Y., Tanji, F., Tsuji, I. (2019). Education level and incident functional disability in elderly Japanese: The Ohsaki Cohort 2006 Study. Plos One, 14(3), e0213386. doi: 10.1371/journal. pone. 0213386 .

Orimo, H., Hideki, I., Suzuki, T., Araki, A., Takayuki, H., Sawabe, M. (2006). Reviewing the definiton of "elderly". Geriatrics and Gerontology International, 6(3), 149-158.

doi: 10.1111/j.1447-0594.2006.00341.x.

Palma, R., Souza de Conti, M.H., Mendosa Quintino, N., Marcia Aparecida, N.G., Penteado Simeao, S.F.A, Vitta, A.D. (2014). Functional capacity and its associated factors in the elderly with low back pain, Acta Ortopedica Brasileira, 22(6), 295-299. doi:10.1590/1413-78522014220600890.

Reuben, D.B., Siu, A.L. (1990). An Objectiove Measure of Physical Function of Elderly Outpatients (The Physical Performance Test). Journal of the American Geriatric Society, 38(10), 1105-1112.

Rubio, E., Lazaro, A., Sanchez-Sanchez, A. (2009). Social participation and independence in activities of daily living: a cross sectional study. BMC Geriatrics, 9, 26. doi:10.1186/1471-2318-9-26. 
Schatz, E., Ralston, M., Madhavan, S., Collinson, M.A., Gomez-Olive, F.X. (2018). Living arrangements, disability and gender of older adults among rural South Africa. Journal of Gerontology: Series B, 73(6), 1112-22. doi:10.1093/ geronb/gbx081.

Schmitter-Edgecombe, M., Parsey, C., Cook, D.J. (2011). Cognitive Correlates of Functional Performance in Older Adults: Comparison of Self-Report, Direct Observation and Performance-Based Measures. Journal of the International Neuropsychological Society, 17(5), 853-864. doi:10.1017/S1355617711000865.

Souza Freitas, R., Fernandes, H.M., Coqueiro, R.D.S., Matos Reis, W.J., Saulo Rocha, V., Brito, T.A. (2012). Functional capacity and associated factors in the elderly: a population study. Acta Paulista de Enfermagem, 25(6), 933-939. doi:10.1590/s0103-21002012000600017.

Suurmeijer, T.P.B.M., Doeglas, D.M., Moum, T., Briancon, S., Krol, B., Sanderman, R., Guillemin, F., Bjelle, A., van der Heuvel, W.J.A. (1994). The Groningen Activity Restriction Scale for Measuring Disability: Its Utility in International Comparisons. American Journal of Public Health, 84(8), 1270-1273. doi:10.2105\%2Fajph.84.8.1270.

Torres, G.D.V., Reis, L.A., Reis, L.A. (2010). Assessment of functional capacity in elderly residents of an outlying area in the hinterland of Bahia/Northeast Brazil. Arquivos de Neuro-Psiquiatria, 68(1), 39-43. doi:10.1590/S0004$282 \times 2010000100009$.

Wales, K., Clemson, L., Lannin, N., Cameron, I. (2016). Functional Assessments Used by Occupational Therapsits with Older Adults at Risk of Activity and Participation Limitations: A Systematic Review. Plos One, 11(2), e0147980.

Wales, K., Lannin, N.A., Clemson, L., Cameron, I.D. (2018). Measuring functional ability in hospitalized older adults: a validation study. Disability and Rehabilitation, 40(16), 1972-1978.

doi: 10.1080/09638288.2017.1323021.

Wild, S., Roglic, G., Green, A., Sicree, R., King, H. (2004). Global prevalence of diabetes: estimates for the year 2000 and projections for 2030. Diabetes care, 27(5), 1047-1053.

World Health Organization (2010). Proposed working definition of an older person in Africa for the MDS Project. Health Statistics and Information Systems. Downloaded 2.2.2020. from www.who.int/healthinfo/survey/ ageingdefnolder/en/index.html.

Young, Y., Boyd, C.M., Guralnik, J.M., Bandeen-Roche, K., Fried, L.P. (2010). Does Self-Reported Function Correspond to Objective Measures of Functional Impairment?. Journal of the American Medical Directors Association, 11(9), 645-653. doi:10.1016/j.jamda.2009.12.084.

Zimmer, Z., House, J. (2003). Education, income, and functional limitation transitions among American adults: contrasting onset and progression. International Journal of Epidemiology, 32(6), 1089-1097. doi:10.1093/ije/ dyg254. 